\title{
Fixed-Cost Models In Manufacturing Glass: The Case Of Juleno Crystals
}

Raida Abuizam, Ph.D., Purdue University Calumet, USA

\begin{abstract}
The Juleno Crystals case illustrates how spreadsheet modeling can be used to solve linear programming problems without the use of algebraic formulations. It also enriches students' knowledge on how to use integer linear programming with binary (0-1) variables in dealing with problems that include fixed costs. Binary variables are often used to transform a nonlinear model into a linear (integer) model. Students completing the Juleno Crystals case will be able to develop a spreadsheet model that will maximize the company's profit while correctly incorporating fixed costs and staying within the limits of the available resources.
\end{abstract}

Keywords: Linear Pprogramming; Integer Linear Programing; Spreadsheet Modeling; Fixed-Cost Models; Optimization; Management Case Study

\section{INTRODUCTION}

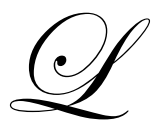

inear programming is a problem-solving approach developed to help managers make decisions. It is a mathematical method for determining a way to achieve the best outcome (such as maximum profit or lowest cost) in a given mathematical model for some list of requirements represented as linear relationships. Linear programming, sometimes known as linear optimization, is the problem of maximizing or minimizing a linear function over a convex polyhedron specified by linear and non-negativity constraints. Simplistically, linear programming is the optimization of an outcome based on some set of constraints using a linear mathematical model.

It is a powerful tool used by operations managers and other managers to obtain optimal solutions to problems that involve restrictions or limitations on their resources. These problems are referred to as constrained optimization problems. Numerous applications of linear programming can be found in today's competitive business environment. It is increasingly important to make sure that a company's limited resources are used in the most efficient way.

In practice, opening a plant or renting a machine requires fixed costs. Fixed cost is encountered if an activity is undertaken at any positive level. Fixed costs imply that the proportionality assumption of linear models no longer holds. Therefore, the use of binary variables $(0,1)$ will help in transforming a nonlinear model into a linear one. This case study will help managers develop a spreadsheet linear programming model that will maximize the company's profit, properly accounting for fixed costs and staying within resource availabilities.

\section{JULENO CRYSTAL COMPANY: CONSIDERING FIXED COST IN MANUFACTURING USING INTEGER AND BINARY VARIABLES IN LINEAR PROGRAMMING}

\section{Case overview}

Juleno Crystals made its debut in 1986 in the European industry. We travel the world to find the best pieces of crystal to supply our clients with the highest quality products. Our crystal glasses are superior value and are guaranteed to be hand cut and mouth blown to be considered a part of the Juleno Crystals' signature collection. We employ master designers to ensure our products uniqueness and exquisiteness. Nothing comes close to matching the light, sparkle, and unique pattern of our premium crystal products. Our tradition of excellence and superior quality will exceed our customer's highest expectations. 
Juleno Crystals is a privately owned company that specializes in producing the finest crystal glasses and vases in the world. Julian Martin, the owner of Juleno Crystals, prefers to focus on providing his customers with signature collections of six different products: Crystal Wine, Crystal Goblets, Champagne Glasses, Sherry Glasses, Brandy Glasses, and Crystal Vases. Each type of these crystal products requires Juleno Crystals to have the appropriate type of machinery. The machinery needed to produce each product must be rented at a monthly rate shown in table 1. This table also lists the amount of Silica $(\mathrm{SiO} 2)$, Lead Oxide $(\mathrm{PbO})$ and labor hours required per unit, as well as the sales price for each type of crystal product.In a given month, 2000 labor hours, 90000 tons of Silica, and 18,000 tons of Lead Oxide are available.The cost for labor is $\$ 10 /$ hour, the cost of Silica (SiO2) per metric ton is $\$ 750$, and the cost of Lead Oxide $(\mathrm{PbO})$ per metric ton is $\$ 2000$.

Table 1: Data for Juleno Crystals

\begin{tabular}{|l|c|c|c|c|c|}
\hline \multicolumn{1}{|c|}{ Product } & Rental Cost & $\begin{array}{c}\text { Labor } \\
\text { Hours/Unit }\end{array}$ & $\begin{array}{c}\text { Silica } \\
\text { Grams/Unit }\end{array}$ & $\begin{array}{c}\text { PbO } \\
\text { Grams/Unit }\end{array}$ & Selling Price \\
\hline Crystal Wine & $\$ 1500$ & 2 & 120 & 28.8 & \\
\hline Crystal Goblets & $\$ 1200$ & 1.5 & 190 & 26.4 & $\$ 35$ \\
\hline Champagne Glasses & $\$ 1600$ & 3.5 & 180 & 43.2 & $\$ 40$ \\
\hline Sherry Glasses & $\$ 1500$ & 4 & 190 & 45.6 & $\$ 41$ \\
\hline Brandy Glasses & $\$ 1550$ & 4.2 & 170 & 40.8 & $\$ 39$ \\
\hline Crystal Vase & $\$ 1600$ & 4 & 190 & 52.6 & $\$ 45$ \\
\hline
\end{tabular}

Julian Martin is requesting your help to do the following:

1. Assuming you can sell all what you can produce, which product or products need to be produced (and in what quantities) in order to maximize profits?

2. If there is a standing order of 100 units of crystal wine glasses every month, which product or products need to be produced and in what quantities? What is the impact on total profit?

3. Given the information for requirement 2, If Juleno Crystals is able to get an extra 2000 tons of the Lead Oxides; does this change affect your recommendations?

4. Given the information for requirement 3, if the fixed rental cost for the Crystal Vase increased to $\$ 1,500$, does this change affect your solution?

5. Use one-way SolverTable to see how the optimal solution in requirement 1 is affected by a change in the available amount of Lead Oxide. Use increments of 500 tons starting from 18,000 until 28,000 tons. Comment on the results.

6. Use two-way SolverTable to see how the optimal solution in requirement 1 is affected by a simultaneous change in the available amount of Lead Oxide and Silica. Use increments of 500 tons starting from 18,000 until 25,000 tons for the Lead oxide and from 90,000 to 97,000 tons for the Silica. Comment on the results.

\section{TEACHING NOTES}

\section{Solution: Spreadsheet Model development}

The variables and constraints required for this model are listed in Table 2. The spreadsheet model for Juleno Crystals is shown in Figure 1.

Table 2: Variables and constraints for Juleno Crystals

\begin{tabular}{|l|l|}
\hline Input Variables & $\begin{array}{l}\text { Recourse usage (labor hours, Silica (SiO2), Lead Oxide (PbO)) per product, Fixed rental costs, selling price, } \\
\text { resource availabilities. }\end{array}$ \\
\hline $\begin{array}{l}\text { Decision } \\
\text { Variables }\end{array}$ & Weather to produce any type of product( binary 0-1), units produced \\
\hline Constraints & $\begin{array}{l}\text { Resources used must be less than or equal resources available } \\
\text { Units produced must be less than or equal logical upper limit(maximum capacity) } \\
\text { Produce any must be binary } \\
\text { Units produced must be integers. }\end{array}$ \\
\hline
\end{tabular}




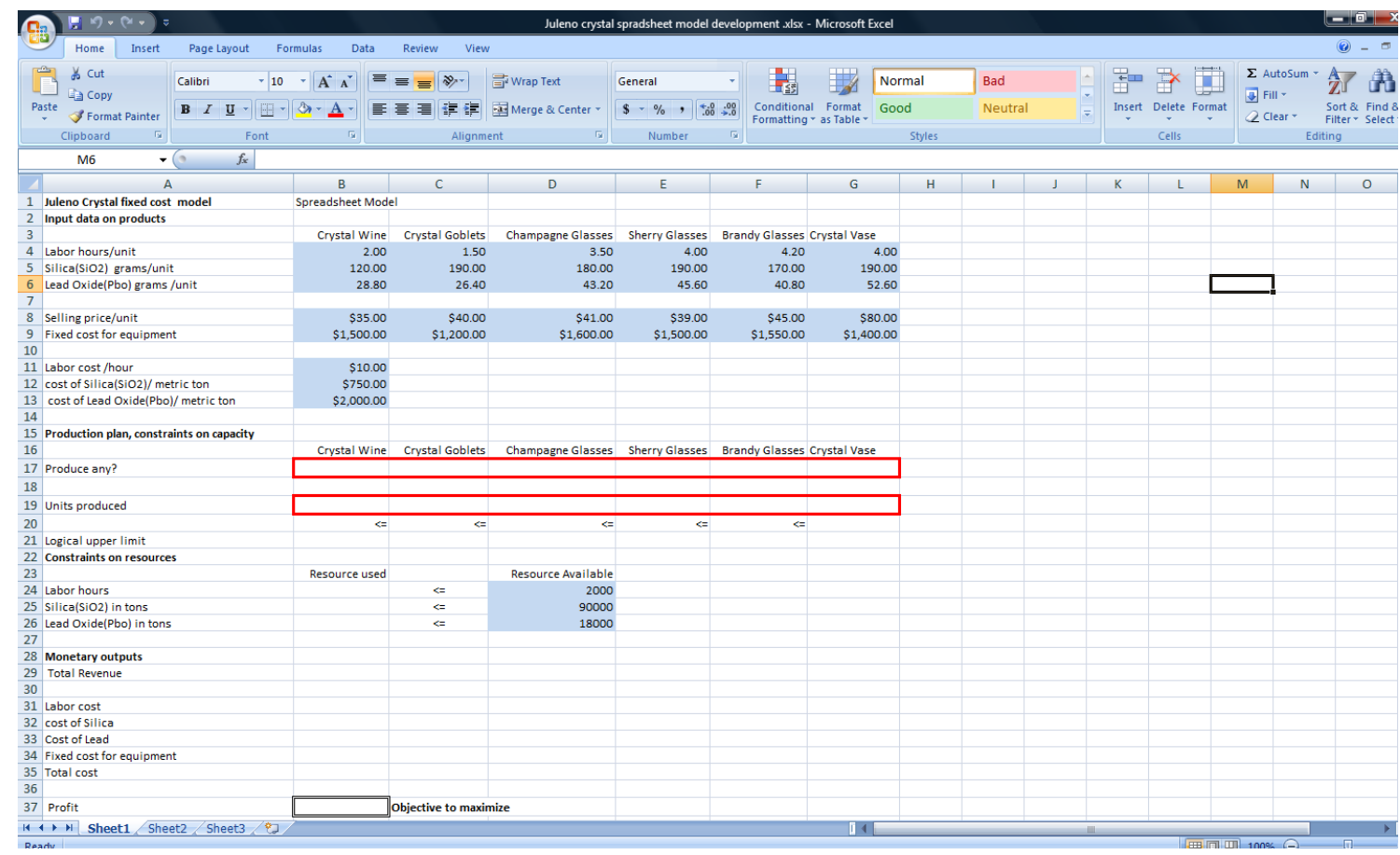

Figure1: Spreadsheet model development

The following steps are needed to develop the spreadsheet model:

1. Inputs. Enter the given inputs in the blue ranges.

2. Binary values for crystal type. Enter binary $0-1$ trial values.

3. Production quantities. Enter trial values in the units produced row.

4. Insert name ranges. Using name ranges will help in copying some formulas. Insert the following name ranges in the specified cells below:

\begin{tabular}{|l|c|}
\hline \multicolumn{1}{|c|}{ Name } & Range \\
\hline Cost_of_Lead & B13 \\
\hline Cost_of_Silica & B12 \\
\hline Labor_cost_hour & B11 \\
\hline Logical_upper_limit & B21:G21 \\
\hline Produce Any & B17:G17 \\
\hline Profit & B37 \\
\hline Resource_Available & D24:D26 \\
\hline Resource_used & B24:B26 \\
\hline Units_produced & B19:G19 \\
\hline
\end{tabular}

5. Effective capacity (Logical upper limit). The model needs to ensure that if the binary variable for any product is 1 , then the fixed cost of renting the appropriate machine is incurred. Also, the units produced should be less than or equal the maximum possible amount that can be produced taking into considerations the limited available resources.

To apply this constraint for Crystal Wine, Crystal wine units produced $<=$ maximum capacity to produce Crystal Wine * (0-1 variable for Crystal Wine). 
The maximum capacity to produce the Crystal Wine will be equal the minimum of \{Available labor hours/Labor hours for Crystal Wine, Available Silica in grams/Silica in grams for each unit of Crystal Wine,Available Lead Oxide in grams/Lead Oxide in grams for each unit of Crystal Wine \}. To implement this logic, calculate the effective capacity for Crystal Wine in cell B21 with the formula B17* MIN $(\$ \mathrm{D} \$ 24 / \mathrm{B} 4,(\$ \mathrm{D} \$ 25 * 1000000) / \mathrm{B} 5,(\$ \mathrm{D} \$ 26 * 1000000) / \mathrm{B} 6)$

Then copy the formula to the range C21:G21.

6. Labor and material used. In cell B24 enter the formula = SUMPRODUCT(B4:G4, Units_produced) to calculated the amount used for labor hours then copy the formula to cells B25 and B26.

7. Monetary output values. Calculate total revenue in cell B29 using this formula =SUMPRODUCT(Units_produced,B8:G8).Calculate total labor cost in cell B31 using this formula =SUMPRODUCT(Units_produced,B4:G4)*Labor_cost_hour.

Calculate total cost of Silica in cell B32 using this formula =SUMPRODUCT(Units_produced,B5:G5)*(cost_of_Silica_SiO2__metric_ton/1000000)Calculate total cost of Lead Oxidein cell B33 using this formula =SUMPRODUCT (Units_produced,B6:G6)*cost_of_Lead_Oxide_Pbo__metric_ton/1000000. Calculate fixed cost in cell B 34 using this formula=SUMPRODUCT(Produce_any?,B9:G9). Calculate total cost in cell B35 using $=\mathrm{SUM}(\mathrm{B} 31: \mathrm{B} 34)$. Finally, calculate the profit by using this formula $=\mathrm{B} 29-\mathrm{B} 35$.

8. Prepare Solver. The Solver dialog box is shown in figure 2. We want to maximize profit by changing produce any and units produced ranges subject to the following constraints:

Produce any $=$ Binary

Units produced $<=$ Logical upper limit

Units produced $=$ Integer

Resources used<= Resources Available

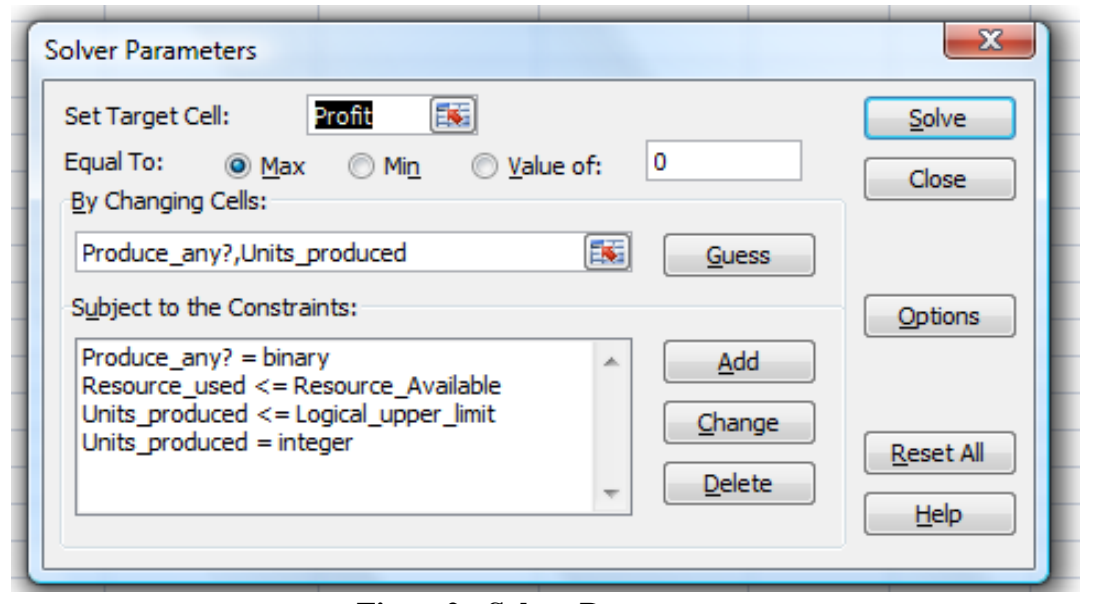

Figure2: Solver Parameters

\section{Solutions to case requirements}

Requirement 1: Assuming you can sell all what you can produce, which product or products need to be produced (and in what quantities) in order to maximize profits? Figure 3 exhibits the solution to requirement 1 . The optimal solution suggests producing 263 units of Crystal Goblets and 210 units of Crystal Vases only. The maximum profit will be equal to $\$ 12,271.62$ 


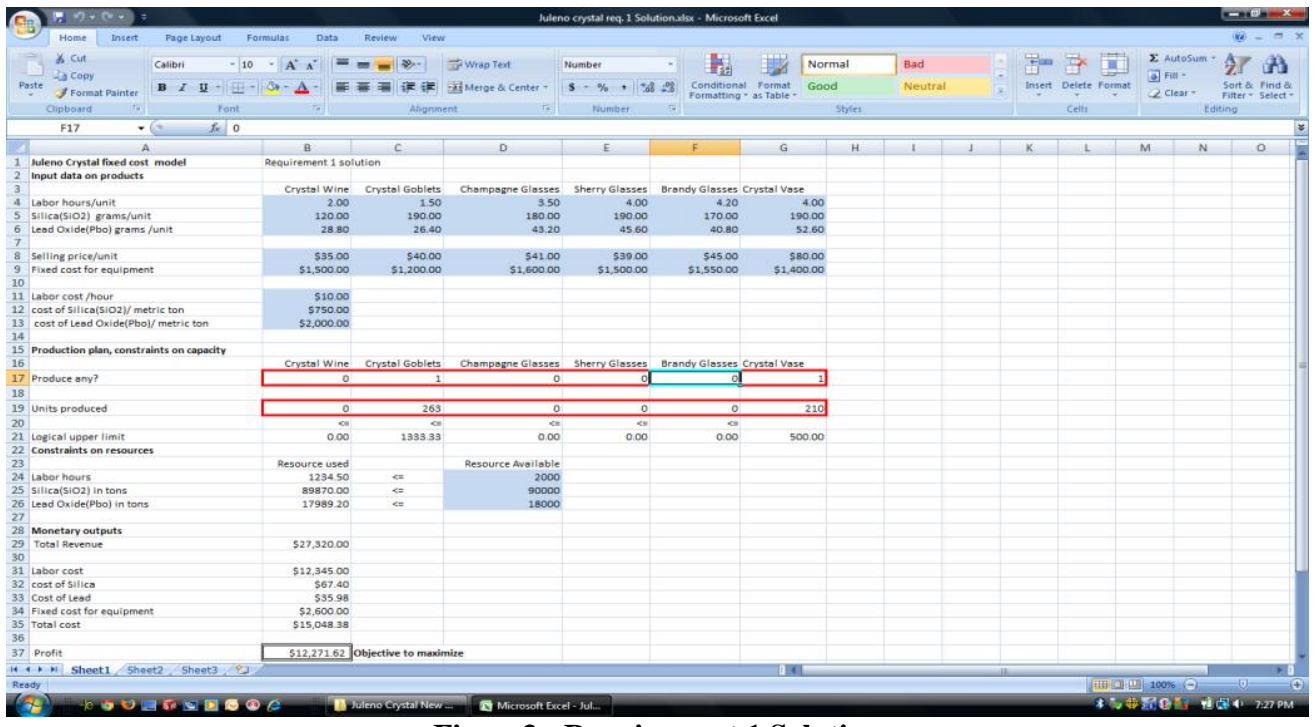

Figure3: Requirement 1 Solution

Requirement 2: If there is a standing order of 100 units of Crystal Wine glasses every month, which product or products need to be produced and in what quantities? What is the impact on total profit?

Figure 4 exhibits the spreadsheet model solution to requirement 2. To solve this requirement, we have to add an additional constraint to satisfy the 100 units demand of Crystal Wine glasses. Figure 5 exhibits the solver dialog box for this scenario. The optimal solution suggests producing exactly100 units of Crystal Wine, 238 units of Crystal Goblets and 168 units of Crystal Vases only. The maximum profit will be equal to $\$ 9,967.15$. Producing 100 units of Crystal Wine glasses reduces the profit by $\$ 2,304.47$.

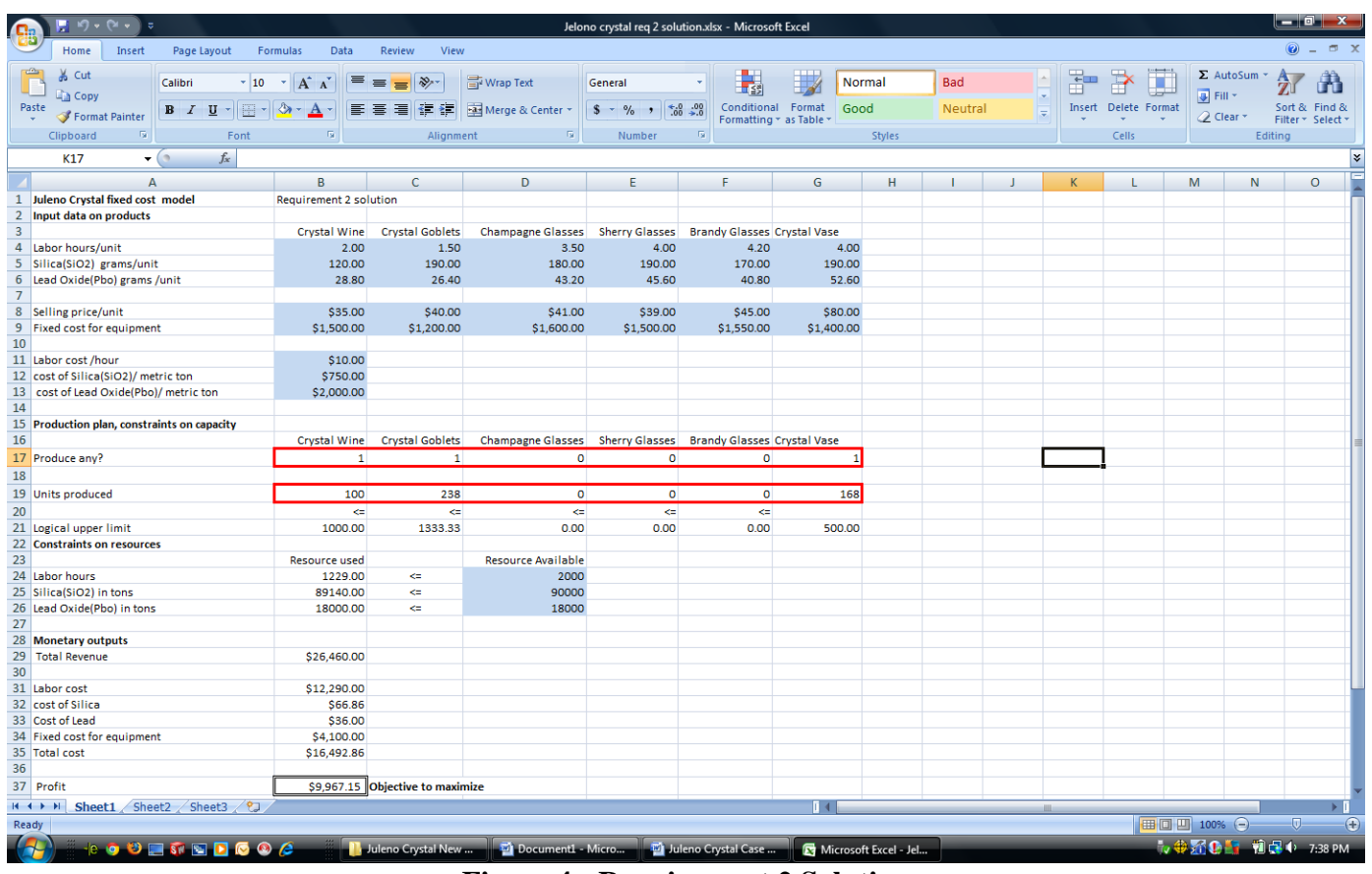

Figure 4: Requirement 2 Solution 


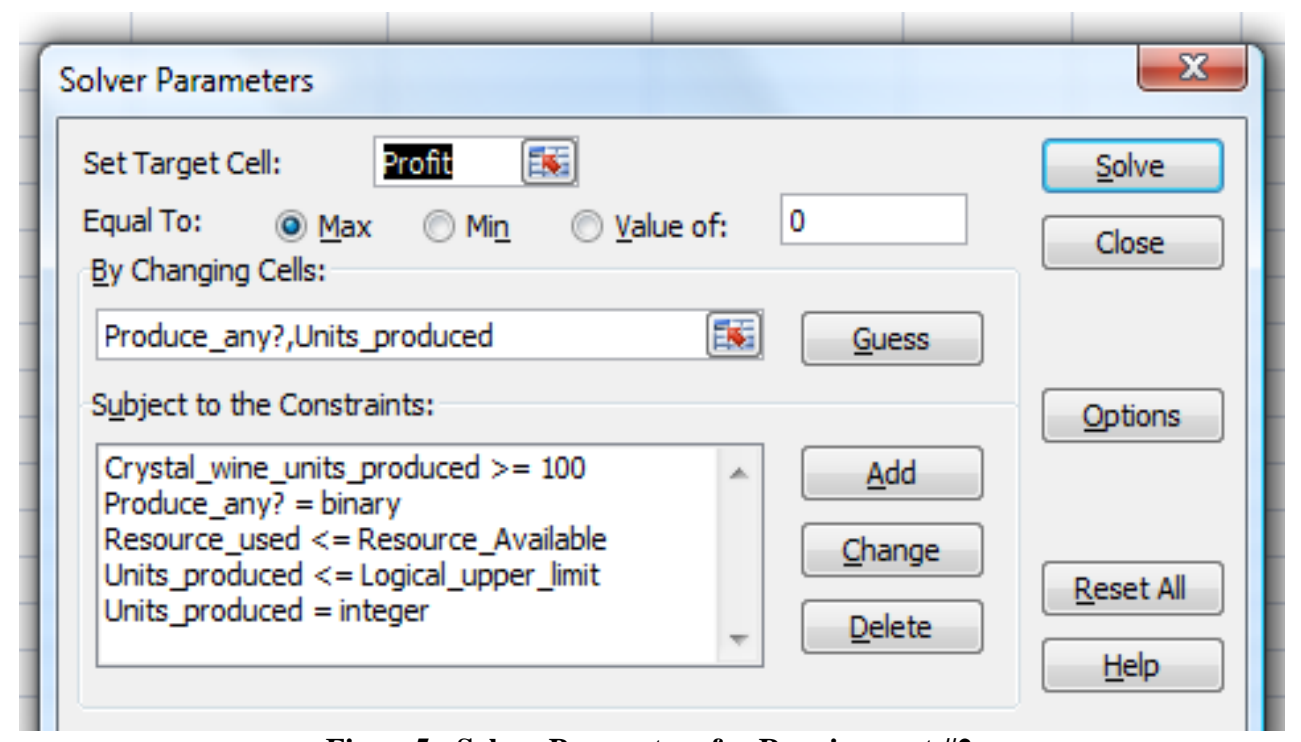

Figure5: Solver Parameters for Requirement \#2

Requirement 3:Given the information for requirement 2, If Juleno Crystals is able to get an extra 2000 tons of the Lead Oxides; does this change affect your recommendations?

Figure 6 exhibits the spreadsheet model solution to requirement 3. To solve this requirement, we have to change the input for the available resources for the Lead Oxide to 20,000 tons instead of 18,000 tons. The optimal solution suggests producing 106 units of Crystal Wine and 322 units of Crystal Vases only. The maximum profit will be equal to $\$ 11,474.60$. The extra 2,000 tons of Lead Oxides increased the profit by $\$ 1,507.45$.

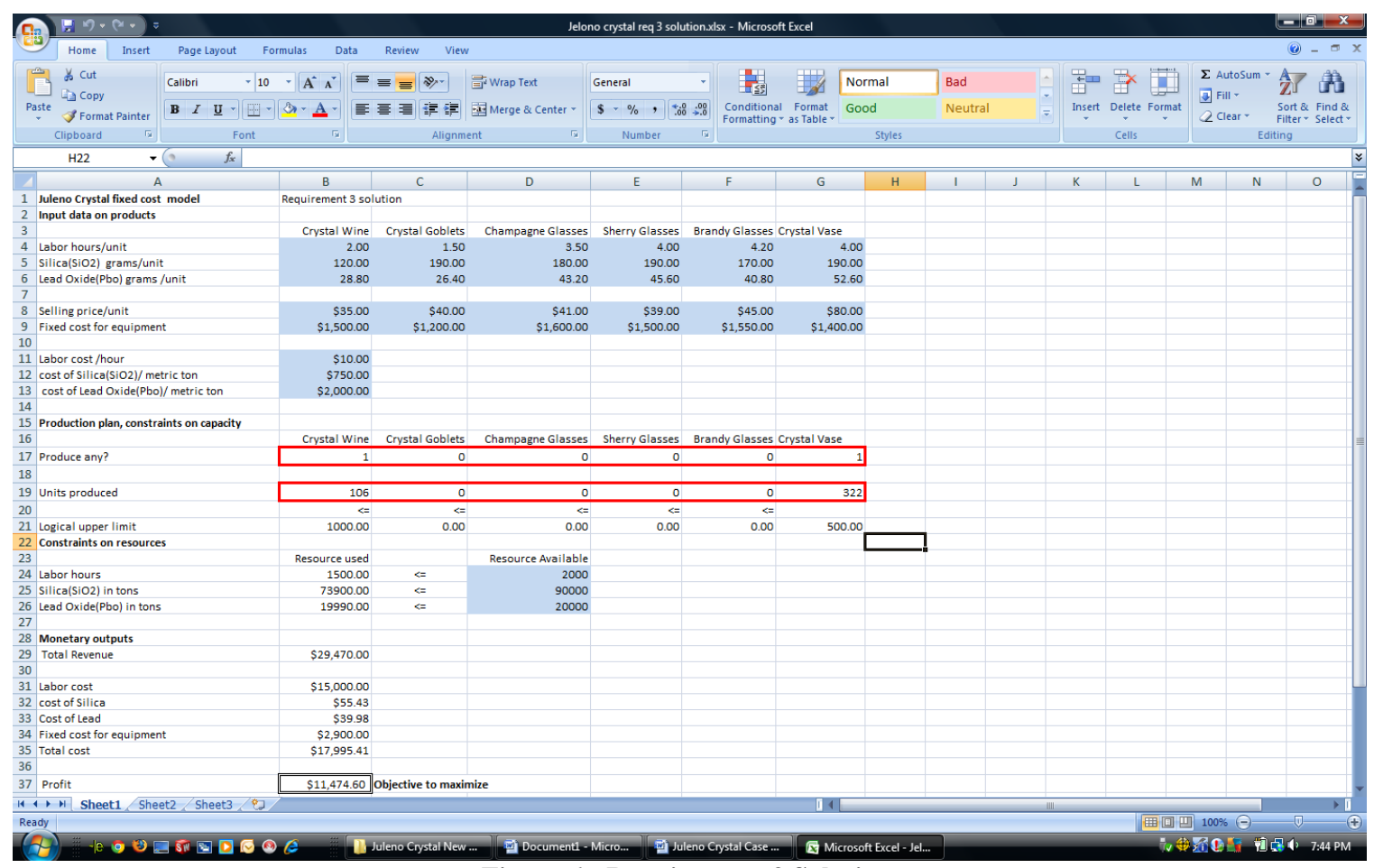

Figure 6: Requirement 3 Solution 
Requirement 4: Given the information for requirement 3, if the fixed rental cost for the Crystal Vase increased to $\$ 1,500$, does this change affect your solution?

Figure 7 exhibits the spreadsheet model solution to requirement 4 . To solve this requirement, we have to change the input for the fixed cost rental for the Crystal Vase. The optimal solution suggests producing 106 units of Crystal Wine and 322 units of Crystal Vases only (please note that the optimal solution did not change compared to requirement 3). The maximum profit will be equal to $\$ 11,374.60$. The extra 100 dollars cost to rent the Crystal Vase machine caused the profit to decrease by $\$ 100$.

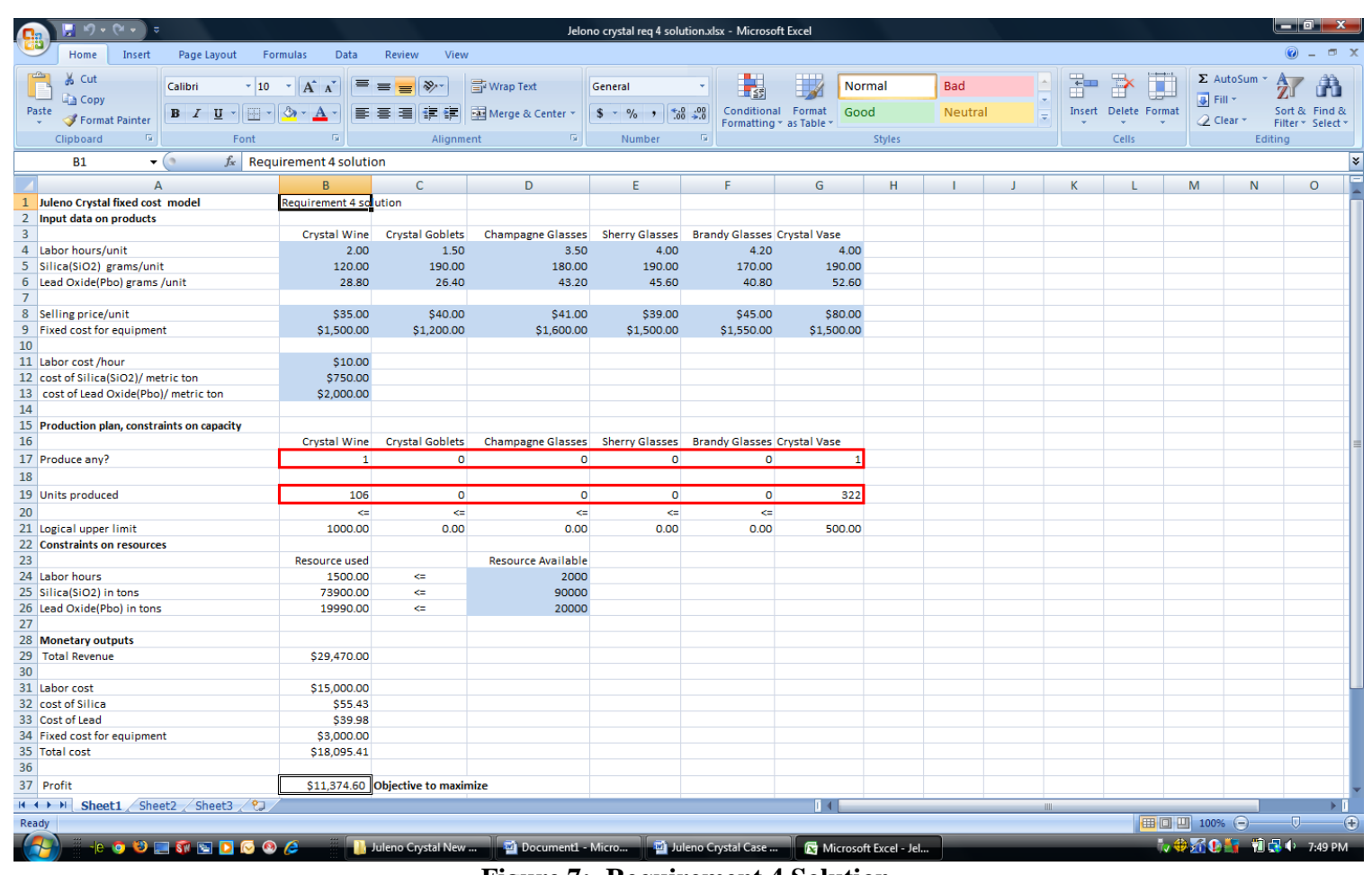

Figure 7: Requirement 4 Solution

Requirement 5: Use one-way SolverTable to see how the optimal solution in requirement 1 is affected by a change in the available amount of Lead Oxide. Use increments of 500 tons starting from 18,000 until 28,000 tons. Comment on the results.

To solve this requirement, we have to download SolverTable. Visit (http://kelley.iu.edu/albrightbooks/Free downloads.htm ) to download SolverTable. Dr. S. Christian Albright has developed an Excel add-Ins called SolverTable. SolverTable allows us to ask sensitivity analysis questions about any of the input variables, not just coefficients of the objective functions and right side of the constraints and it provides straightforward answers. Figure 8 exhibits the one-way SolverTable dialog box.

When the available amount of Lead Oxide equal to 18000 tons, the solution suggested producing 263 units of Crystal Goblets and 210 units of Crystal vases. The profit for this scenario is $\$ 12,271.62$. When the amount of available Lead Oxide increased to 18500 tons, the solution suggested producing 244 units of Crystal Goblets and 229 units of Crystal vases. The profit for this scenario is $\$ 12,555.62$.

By incrementally increasing the amount of Lead Oxide available, the solution suggested producing Crystal vases only. The amount to produce kept increasing until it reached 473 units at 2500 tons available and it stopped because other scarce resources are gone at this point. The highest profit achieved at this level was $\$ 17,402.84$. Figure 9 exhibits SolverTable solution to requirement 5. 


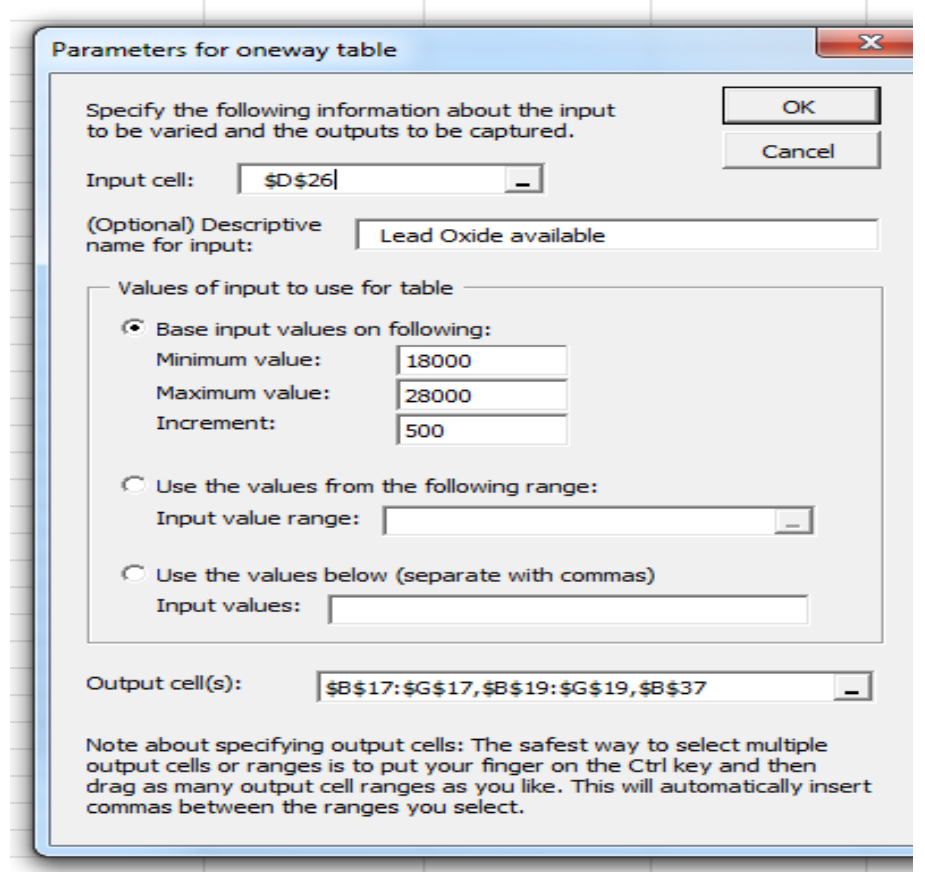

Figure 8: One-Way SolverTable Dialog Box

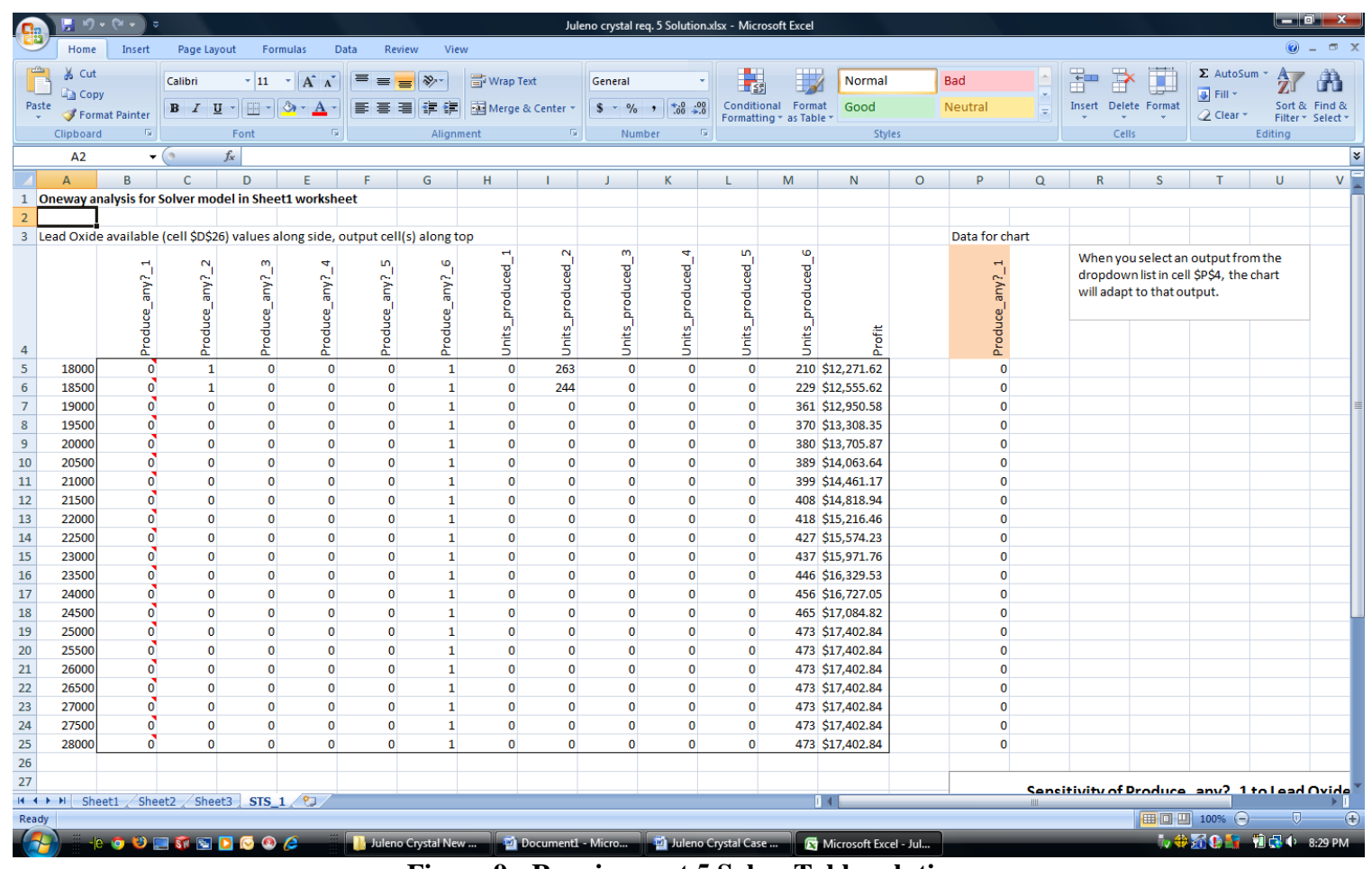

Figure 9: Requirement 5 SolverTable solution

Requirement 6: Use two-way SolverTable to see how the optimal solution in requirement 1 is affected by a simultaneous change in the available amount of Lead Oxide and Silica. Use increments of 500 tons starting from 18,000 until 25,000 tons for the Lead oxide and from 90,000 to 97,000 tons for the Silica. Comment on the results. 
To solve this requirement, we need to use Two-Way SolverTable. Two of the input variables are changing simultaneously. Figure 10 exhibits two-way SolverTable dialog box.

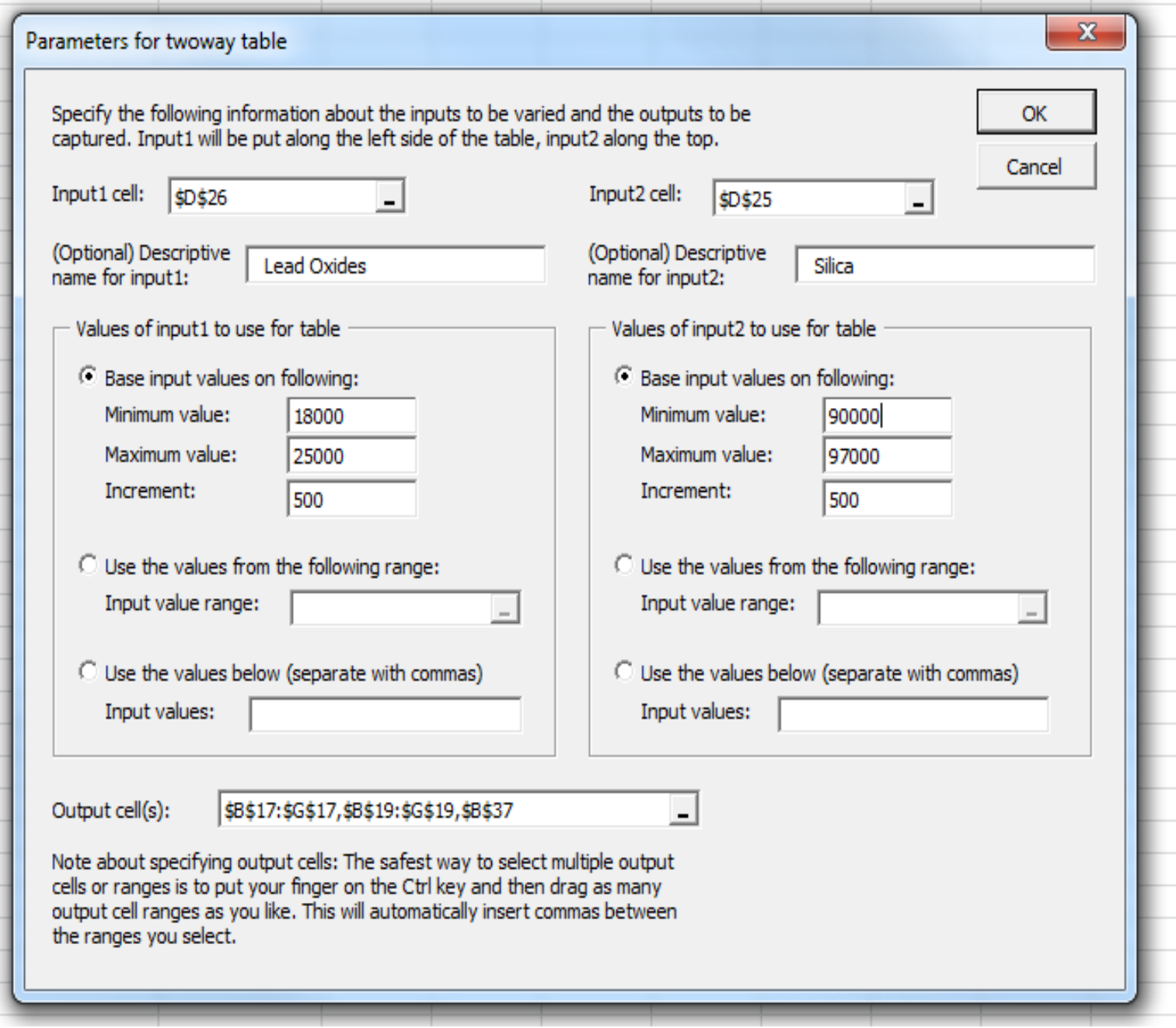

Figure 10: Two-Way SolverTable Dialog Box

At the levels of 18,000 and 18,500 tons of Lead Oxide, the solution suggested to produce Crystal Goblets and Crystal Vases. At 19,000 tons, the solution suggested to produce Crystal Goblets only when Silica has increased to 92,500 tons. The solution always suggested producing Crystal Vases at all levels as shown in figure 11. The highest amount of profit possible is equal to $\$ 17,482.34$. Figure 12 exhibits a graph that reveals sensitivity analysis of profit to both Silica and Lead Oxides. 

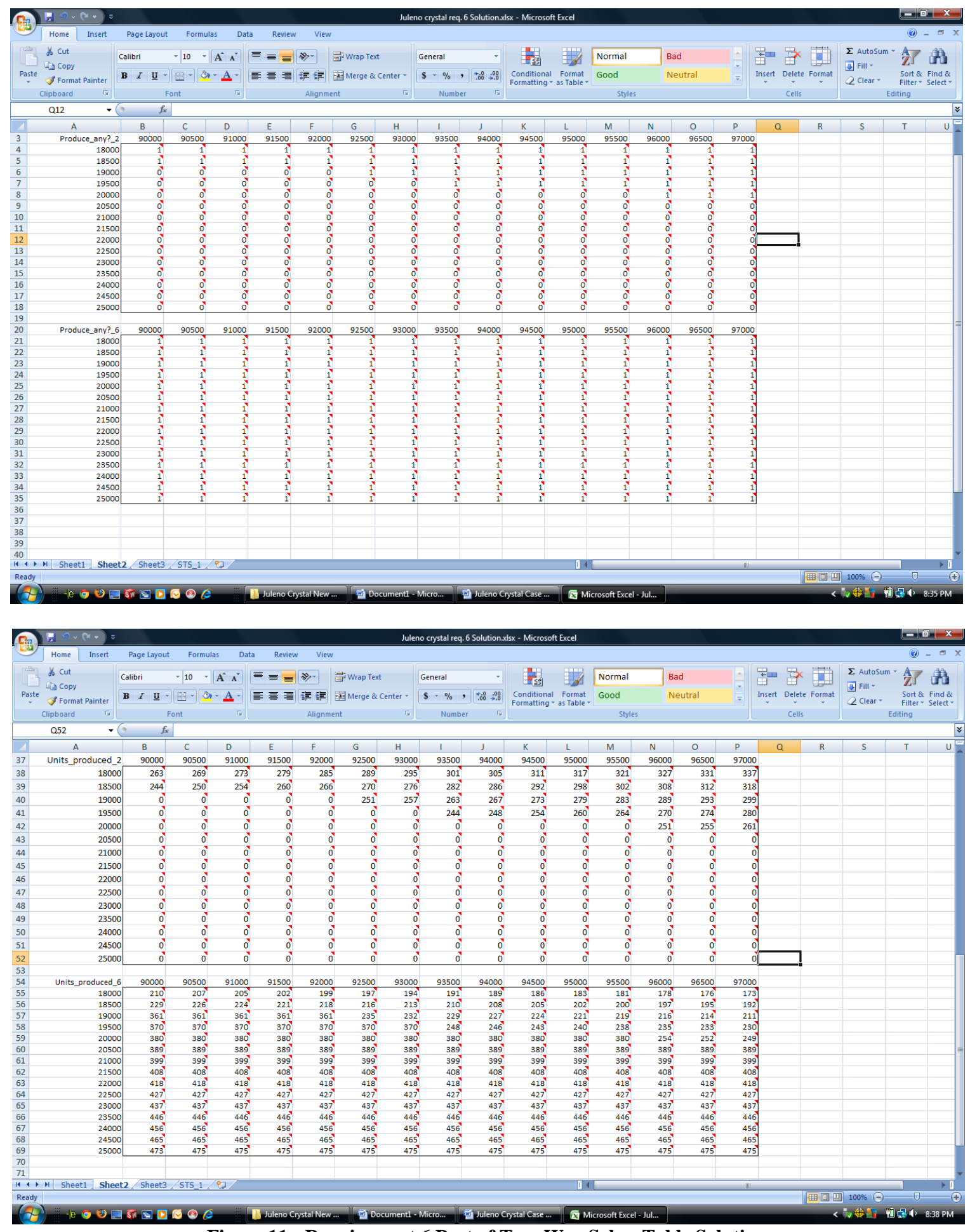

Figure 11: Requirement 6 Part of Two-Way SolverTable Solution 


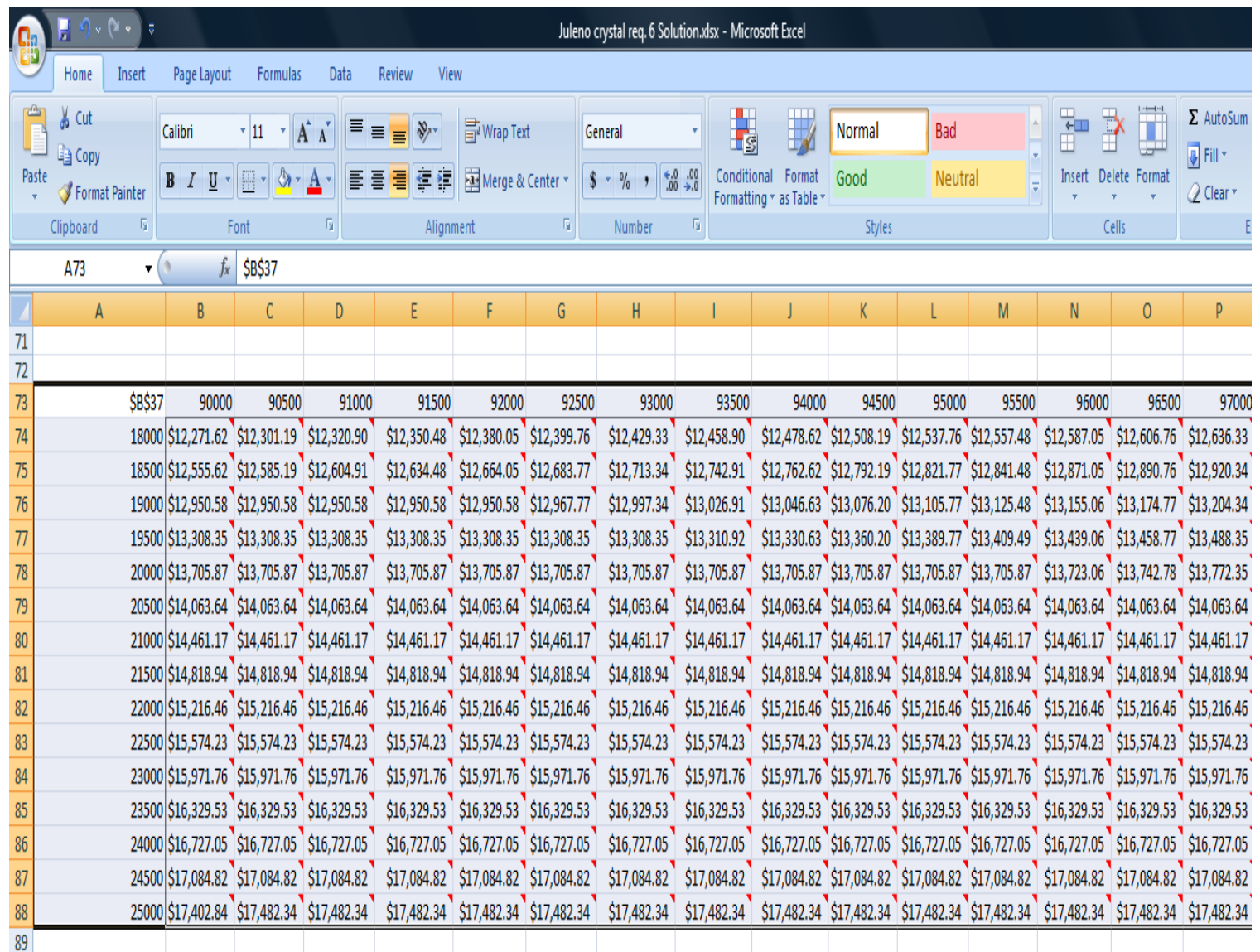

Figure 11: Continued, Requirement 6 Part of Two-Way SolverTable Solution

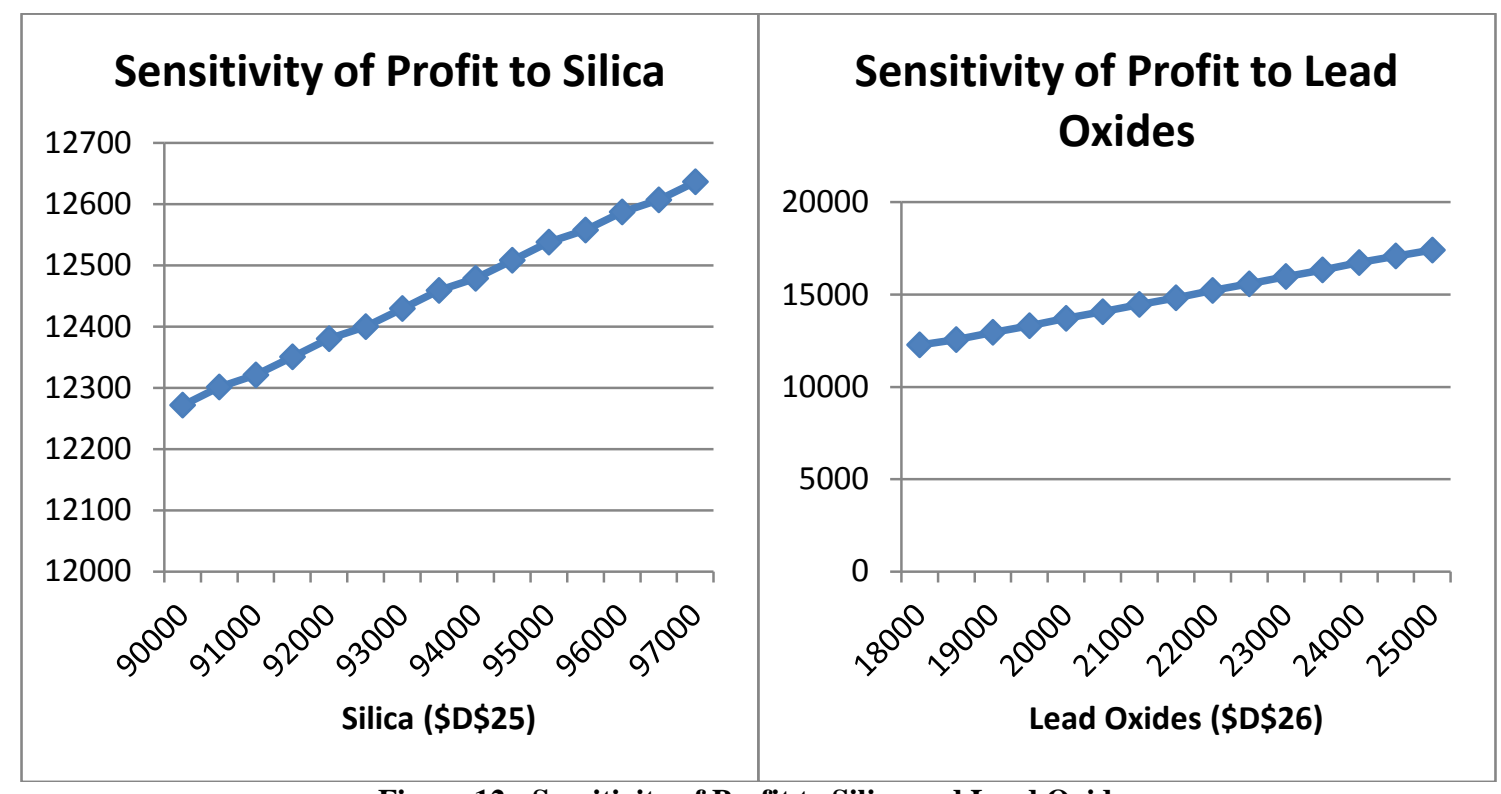

Figure 12: Sensitivity of Profit to Silica and Lead Oxides 


\section{Learning Objectives}

1. To develop a spreadsheet linear programming model to maximize profit without the need to formulate the problem algebraically.

2. To use integer and binary variable (0-1) to correctly account for the fixed costs. Fixed cost models are nonlinear; therefore, the use of binary variables will transform a nonlinear model into a linear one.

3. To use one-way SolverTable to monitor the sensitivity of the optimal model toward any changes made to a single input.

4. To use two-way SolverTable to monitor the sensitivity of the optimal model toward any changes made to a pair of inputs.

\section{AUTHOR INFORMATION}

Raida Abuizam is an Associate professor of Operations Management in the Department of Finance and Economics at Purdue University Calumet, Hammond Indiana, USA. E-mail: abuizam@ @urduecal.edu

\section{REFERENCES}

1. Albright, S. Christian and Wayne L. Winston, Spreadsheet modeling and Applications, Thompson/Brooks Cole, Belmont California, 2005.

2. Albright, S. Christian and Wayne L. Winston, Practical Management Science, Revised third edition, South-Western Cengage Learning, Mason, Ohio, 2009.

3. Ragsdale, T. Cliff, Spreadsheet Modeling \&Decision Analysis: A practical Introduction to Management Science, Fourth edition, ThomsonSouth-Western, Mason, Ohio, 2004.

4. Stevenson, J. William, Operations Management, Tenth Edition, McGraw-Hill Irwin, New York, New York, 2009. 